8

9

10

11

12

13

14

15

16

17

\section{Dairy Manure Resource Recovery utilizing Two-stage Anaerobic Digestion - Implications of Solids Fractionation}

\author{
Edmond J. Stowe ${ }^{1}$, Erik R. Coats ${ }^{2}$, Cynthia K. Brinkman ${ }^{3}$
}

Submitted to:

Bioresource Technology

July 2015

Revised September 2015

\footnotetext{
${ }^{1}$ Mountain Waterworks, Boise, ID (at the time of the research, was a graduate student in the Department of Civil Engineering, University of Idaho, Moscow, ID).

${ }^{2}$ Department of Civil Engineering, University of Idaho, Moscow, ID, USA 83844-1022. Correspondence concerning this paper should be addressed to him at Phone: (208) 885-7559; FAX: (208) 885-6608; email: ecoats@uidaho.edu

${ }^{3}$ Department of Civil Engineering, University of Idaho, Moscow, ID, USA 83844-1022.
} 
Abstract.

Dairy manure management is increasingly becoming an environmental challenge. In this regard, manure anaerobic digestion $(\mathrm{AD})$ can be applied to address environmental concerns;

21 however, dairy manure AD remains economically uncompetitive. Ongoing research is focused

22 on enhanced resource recovery from manure, including maximizing AD methane yield through a

23 novel multi-stage AD configuration. Research presented herein centered on the hypothesis that

24 separately digesting fine and coarse solids from fermented dairy manure would improve methane

25 production; the hypothesis was disproven. While maximum methane concentration was realized

26 on fine solids, combined solids AD yielded enhanced VS destruction. The diverse combined-

27 solids substrate enriched for a more heterogeneous bacterial/archaeal consortium that balanced

28 fermentation and methanogenesis to yield maximum product (methane). However, results

29 suggest that targeted $\mathrm{AD}$ of the fat-rich fine solids could be a more optimal approach for

30 processing manure; alternate (non-AD) methods could then be applied to extract value from the

31 fibrous fraction.

32

33 Key Words. anaerobic digestion; volatile fatty acids (VFAs); dairy manure;

34 hydrogenotrophic/acetoclastic methanogens; quantitative polymerase chain reaction (qPCR) 35 


\section{Introduction}

Based on the agricultural census, in 2007 there were 71,510 dairy operations in the United States housing 9.158 million cows and producing an estimated 500 billion pounds of wet manure yearly (Betts \& Ling, 2009); additional cows have since been added to the working herds. Regarding byproducts management, as a legacy practice dairy manure is predominantly

41 land applied to enhance forage crop production, with high levels of nitrogen, phosphorus, and

42 other nutrients enhancing plant growth (USDA-NRCS, 2012). However, this approach is

43 becoming increasingly problematic due in part to concerns regarding climate change caused by

44 greenhouse gas $(\mathrm{GHG})$ accumulation. Microbial metabolism of land applied manure releases

45 significant amounts of methane and nitrous oxide to the atmosphere (EPA, 2014); both are potent

46 GHGs (EPA, 2014). GHG emissions associated with dairy manure management account for

$47 \quad 7.0 \%$ of agricultural sector emissions according to the most recent U.S. EPA estimates (EPA,

48 2014). Recognizing this concern, in January 2009 the Innovation Center (IC) for U.S. Dairy

49 announced a voluntary goal to reduce dairy GHG emissions 25\% by 2020.

Beyond GHG emissions, challenges associated with conventional manure storage and

51 land application practices include emission of unpleasant odors, potential nutrient migration to

52 surface and ground water, and potential cross-contamination of crops with pathogenic organisms

53 present in land-applied manure (Sahlstrom, 2003). These challenges have been exacerbated in

54 recent years through consolidation of the U.S. dairy industry, which has increased manure

55 densities (geographically). Public opposition to large dairy operations based on offensive odors,

56 waste management, and environmental concerns has made it increasingly difficult for dairy

57 operators to build new facilities or expand existing ones (Sanders et al., 2010). 
Anaerobic digestion (AD) is an established waste treatment technology that can be applied to address many of the manure management environmental concerns. AD leverages an interdependent consortium of anaerobic microorganisms to break down complex organic wastes

61 and produce a biogas consisting primarily of methane and carbon dioxide. The methane

62 produced can be combusted to generate heat and electricity, which reduces GHG emissions

63 through conversion of methane to carbon dioxide and by decreasing demand for fossil fuels. AD

64 also provides pathogen reduction and can be used to produce EPA Class A or B biosolids (EPA, 65 2003). Finally, digestate is rich in ammonium, which is readily assimilated by plants when 66 applied at agronomic rates, and it contains lower concentrations of volatile compounds

67 responsible for objectionable odors than untreated manure (Betts \& Ling, 2009; Weiland, 2010).

68 The combination of pathogen and odor reduction, increased nutrient availability, and reduced

69 GHG emissions make anaerobically digested manure a superior choice to untreated manure for 70 land application.

71 In considering deployment of ADs at dairies, it is estimated that such installations are

72 feasible at over 8,000 U.S. dairy, swine, and poultry operations. However, only about $2 \%$ of the 73 sites where AD is feasible actually have digesters installed (EPA, 2010). U.S. farmers generally 74 avoid anaerobic digesters for a variety of reasons, with high initial cost and low or negative rate 75 of return on investment being the most common (Faulhaber et al., 2012; Zaks et al., 2011).

76 Indeed, studies have shown new AD projects will probably require some form of government 77 market support in order to be profitable, such as carbon offset credits, low interest loans, or 78 grants to compensate for low energy prices and the high initial cost of digester facilities 79 (Faulhaber et al., 2012; Zaks et al., 2011). 
If improvements could be made to the AD process, both in terms of improving digester methane yield and in developing complementary processes capable of producing additional

82 revenue streams, its benefits could be more broadly realized. With this goal in mind, ongoing

83 research has been exploring the potential for diversifying the commodity portfolio from manure

84 waste streams (Coats et al., 2013). Central to the proposed integrated suite of processes is a novel

85 two-stage anaerobic digestion process, which utilizes a fermenter and digester operated in series

86 to separate manure hydrolysis and fermentation from methanogenesis in order to optimize the

87 environment for the microbes responsible for each process (Coats et al., 2012). Within this

88 integrated system, a portion of the volatile fatty acid (VFA)-containing liquid fraction generated

89 in the fermenter is diverted from the digester and used as substrate in the production of

90 polyhydroxyalkanoates (PHAs; a high-value bioplastic) by mixed microbial cultures (Coats et

91 al., 2007; Wei et al., 2014), while the remaining liquid and residual solids are directed to an AD

92 to produce methane (Coats et al., 2012).

With ongoing efforts to continuously enhance resource recovery from the proposed

94 integrated suite of processes, investigations of this novel AD operation highlighted potentially

95 useful process improvements associated with solids fractionation. Specifically, screening was

96 applied to separate the carboxylate-rich liquid fraction from coarse, lignocellulosic residual

97 solids (referred to hereafter as "coarse solids"). Applying this solids separation method, particles

98 small enough to pass through the one millimeter mesh screen could be separately isolated by

99 subsequent centrifugation; the residual solids material present in the screened effluent is

100 hereinafter referred to as "fine solids." Preliminary investigations indicated the fine solids

101 exhibited the potential to yield higher methane content biogas when digested separately from the 102 coarse solids ( $\sim 69 \%$ vs. $\sim 55 \%$ (by volume)). Moreover, microbial population analyses 
103 demonstrated the ADs would select and enrich for fermenting bacterial consortia specialized in

104 degrading the unique substrates (fine vs. coarse solids), thereby ensuring process stability

105 (Briones et al., 2014). Building upon these investigations, the research presented and discussed

106 herein focused on detailed interrogation of enhanced solids phase-separation AD. Research was

107 driven by the hypothesis that separate AD of the two distinct solids streams (fine vs. coarse)

108 would increase system-level methane production (both in concentration and yield) because the

109 ADs would be microbially tailored to the respective substrates. Research objectives were to i)

110 comprehensively assess methane production potential of the separated fine and coarse residual

111 solids fractions, ii) assess overall performance of the contrasting respective AD configurations,

112 iii) evaluate the microbial populations in the $\mathrm{AD}$ systems, and iv) make a final determination for

113 combined vs. separate solids AD.

\section{2. Material and Methods}

\section{$115 \quad 2.1$ Experimental Design}

Two phase-separated AD systems, referred to as Systems 1 and 2, were operated to

117 conduct the investigations (illustrated in Figures 1a and 1b). Each "system" received the same

118 volatile solids (VS) loading rate, with identical total operational volumes (20 L fermenter, $40 \mathrm{~L}$

119 digester, 60 L total). Reactor SRTs were also equivalent in each system (4 day fermenter, 20 day

120 digester). Thus, the dominant factor which varied between the systems was the substrate. The

121 substrate for System 2 was separated into two fractions, one containing primarily large, coarse

122 solids, and the other small, fine solids, while the substrate to System 1 was not fractionated.

123 System 1 (Fig. 1a) was operated as the experimental control and consisted of a fermenter (F6-c),

124 and a digester (AD6-c) which received the centrifuge-separated (i.e., containing both coarse and

125 fine particles) solids fraction of the fermenter effluent. System 2 (Fig. 1b) consisted of a 
126 fermenter (F3-c) and two independent digesters AD3-c and AD8, which were operated in

127 parallel. AD3-c received the coarse solids fraction of the fermenter effluent, which was separated

128 by screening. AD8 received the fine solids fraction, which was produced via centrifugation of the

129 screened fermenter liquor. To ensure steady state conditions prevailed during operational

130 performance assessment, both systems were allowed to equilibrate for 80 days (equivalent to 4

131 digester SRTs) prior to the start of data collection. Steady state conditions were defined based on

132 observed stable AD biogas production and low effluent VFA concentrations, both of which were

133 monitored regularly during the equilibration period. Once steady state conditions were achieved,

134 data was collected during a subsequent 85 day operational period (equal to 4.25 digester SRTs).

135 The length of this period was sufficient to identify statistically significant differences in

136 performance between the two AD systems.

\section{$137 \quad 2.2$ Source of Manure}

Raw dairy manure was collected from the floor of the University of Idaho dairy every one to two weeks, sampled for total and volatile solids content (TS/VS) at the time of collection, and stored at $4{ }^{\circ} \mathrm{C}$ until use. Collection of manure from areas of the dairy where it would likely

141 be mixed with refractory lignocellulosic bedding material was avoided.

\section{$142 \quad 2.3$ Fermenter Design and Operation}

Construction of both fermenters was identical. The reactor vessels were $22.7 \mathrm{~L}$ (6 gallon)

144 HDPE buckets with valves installed in the base for wasting, and sealed with HDPE lids

145 containing rubber gaskets. Both were operated at an active volume of $20 \mathrm{~L}$, a 4-day SRT, and a target OLR of $8.75 \mathrm{~g} \mathrm{VS} / \mathrm{L}^{*} \mathrm{~d}$, with feeding/wasting conducted once per day. The target OLR

147 was maintained based on VS samples collected from the raw manure, and the feed consisted of a 148 mixture of raw dairy manure and sufficient tap water to bring the total feed volume to $5 \mathrm{~L}$. 
149 Fermentation occurred at room temperature $\left(22-25^{\circ} \mathrm{C}\right)$. Mixing was accomplished using $9.53 \mathrm{~cm}$

150 (3.75 inch) diameter helical impellers driven by Oriental Motor (San Jose, CA, USA) USM315-

151 401W 15-watt AC variable speed motors connected to 3GN35SA reduction gearboxes, and

152 operated at a speed sufficient to provide uniform mixing. To minimize exposure of the

153 fermenters to oxygen, gasketed bulkhead fittings were used to install draft tubes constructed of

154 Schedule $401.9 \mathrm{~cm}(3 / 4 \mathrm{inch})$ PVC pipe through the lids and extending below the liquid surface.

155 Each fermenter contained two tubes, one housing the impeller shaft and the other used for

156 feeding. Biogas produced was vented through the lids via tubing connected to an airlock. The

157 five liters of effluent produced daily from F6-c was centrifuged at $8000 \mathrm{rpm}$ for five minutes at

158 room temperature to separate liquid and solid fractions. Coarse solids were recovered from the

159 F3-c effluent by screening through a strainer with a mesh size of approximately one mm (Norpro

160 Inc., Everett, WA). The fermenter liquor passing through the strainer was centrifuged at 8000

$161 \mathrm{rpm}$ for 5 minutes at room temperature to recover the fine solids.

\section{$162 \quad 2.4$ Anaerobic Digester Design and Operation}

Substrate for AD6-c was prepared using the separated solids from F6-c and sufficient

164 centrifuged fermenter liquor to yield two liters. Substrate for digester AD3-c was batched using

165 the solids retained on the strainer along with sufficient centrifuged fermenter liquor to yield 1.5 L

166 of influent substrate, while that of AD8 consisted of the fine solids and sufficient centrifuged

167 liquid to make $0.5 \mathrm{~L}$. The remaining liquid effluent from both F3-c and F6-c was diverted to

168 PHA production experiments (not part of this study).

169

Digesters AD3-c and AD6-c were operated at a 20-day SRT with active volumes of $30 \mathrm{~L}$

170 and $40 \mathrm{~L}$, respectively. The reactors were constructed from Chem-Tainer $56.8 \mathrm{~L}$ (15 gallon) cone

171 bottom HDPE tanks (West Babylon, NY, USA) fitted with a polypropylene lid and sealed using 
172 RTV silicone gasket sealant. Sections of $1.9 \mathrm{~cm}(3 / 4 \mathrm{inch})$ diameter PVC pipe were used as draft

173 tubes to allow feeding and mixing while maintaining anaerobic conditions. The digesters were

174 mixed using $15.24 \mathrm{~cm}$ (6 inch) diameter two-blade impact-resistant plastic propellers driven by

175 Oriental Motor (San Jose, CA, USA) BHF62AT-50 40-watt AC variable speed motors connected

176 to 5GN3.6SA reduction gearboxes. The mixing intensity generated was sufficient for

177 homogenization, although a floating scum layer approximately 5-7.5 $\mathrm{cm}$ (2-3 inches) thick

178 developed on the surface of AD6-c. The digesters were heated by circulation of hot water

179 through $15.24 \mathrm{~m}$ (50 foot) sections of $0.95 \mathrm{~cm}$ (3/8 inch) diameter copper tubing wrapped around

180 the exterior of the tanks. The hot water cycling frequency was dictated by a programmable logic

181 controller (PLC) connected to resistance temperature detector (RTD) probes installed in each

$182 \mathrm{AD}$, which maintained digester temperature at $35^{\circ} \mathrm{C}$.

183

Digester AD8 was constructed from a square 18.9 L (5 gallon) medium density

184 polyethylene (MDPE) tank with a pyramidal base (Den Hartog Industries, Hospers, IA, USA).

185 Feeding and mixing utilized $1.9 \mathrm{~cm}(3 / 4 \mathrm{inch})$ diameter PVC draft tubes to maintain anaerobic

186 conditions. Mixing was provided by a $10.2 \mathrm{~cm}$ (4 inch) diameter three-blade stainless steel

187 propeller driven by an Oriental Motor USM315-401 15-watt AC variable speed motor using a

188 36N5SA reduction gearbox (Oriental Motor, San Jose, CA, USA). The mixing speed was

189 constant and of sufficient intensity to ensure homogenization. The digester was heated using two

$190 \quad 12.7 \mathrm{~cm} \times 25.4 \mathrm{~cm}$ (5 inch x $10 \mathrm{inch})$ silicone rubber heaters rated at 120V/63W (Watlow

191 Electric Manufacturing Co., St. Louis, MO, USA). Heater cycling was controlled with a

192 proportional/integral/derivative (PID) controller (Red Lion Controls, York, PA, USA) connected

193 to a RTD temperature probe to maintain digester temperature at $35^{\circ} \mathrm{C}$. 

into the gas exhaust lines of all digesters to allow the headspace volume to vary during feeding and wasting.

\subsection{Analytical Techniques}

Digester gas production was quantified using wet tip gas meters (Wet Tip Gas Meter Co., Nashville, TN, USA). One meter was attached to each digester, although during the latter 48 days of the 85 day experiment the gas exhaust lines of AD3-c and AD8 were spliced together and the combined production was measured by a single meter.

Methane, carbon dioxide, and nitrogen content of the digester gas were quantified daily by gas chromatography using a Gow-Mac (Bethlehem, PA, USA) Series 550P Gas Chromatograph equipped with a thermal conductivity detector (TCD). The temperature of the column (Grace Davison Discovery Sciences, Deerfield, IL, USA, Alltech ${ }^{\circledR}$ Hayeseop ${ }^{\circledR}$ DB $100 / 120,30 \mathrm{ft} \times 1 / 8$ in. $\mathrm{x} 0.085$ in., stainless steel) was held constant at $70^{\circ} \mathrm{C}$, and the injector temperature constant at $39^{\circ} \mathrm{C}$. The detector was operated at $160^{\circ} \mathrm{C}$ with $180 \mathrm{~mA}$ current. Helium was used as the carrier gas at a flow rate of $22 \mathrm{~mL} / \mathrm{min}$, and $0.6 \mathrm{~mL}$ samples were injected using a gas-tight syringe (SGE Analytical Science, Austin, TX, USA).

Samples collected for quantification of VFAs were centrifuged at 15,000 rpm for 20

minutes and the supernatant was passed through a 0.22 micron PVDF syringe filter (Millipore Corp., Billerica, MA, USA). Filtered samples were acidified using 80 to $100 \mu \mathrm{L}$ of $2 \mathrm{~N} \mathrm{HNO}_{3}$ depending on sample alkalinity in order to shift the $\mathrm{pH}$ to approximately 2 and VFA speciation to the volatile, protonated form. VFA concentrations were measured using a Hewlett-Packard (Palo Alto, CA, USA) 6890 series gas chromatograph and flame ionization detector. The column was a Grace (Grace Davison Discovery Sciences, Deerfield, IL, USA) AT ${ }^{\mathrm{TM}}$-AquaWax-DA (30 m x 
$2170.25 \mathrm{~mm}$ ) capillary column (PN 14537). Samples were injected using the Hewlett-Packard model

2187679 auto-injector equipped with a $5 \mu \mathrm{L}$ syringe using an injected volume of $0.5 \mu \mathrm{L}$ in a 1:20

219 split ratio using helium as the carrier gas at a flow rate of $1.2 \mathrm{~mL} / \mathrm{min}$ and nitrogen as the

220 makeup gas. The temperature program used consisted of heating the oven to $50^{\circ} \mathrm{C}$ for $2 \mathrm{~min}$,

221 ramp at $25^{\circ} \mathrm{C} / \mathrm{min}$ to $95^{\circ} \mathrm{C}$, then ramping at $10^{\circ} \mathrm{C} / \mathrm{min}$ to $150^{\circ} \mathrm{C}$, hold $3 \mathrm{~min}$, ramping at $25^{\circ} \mathrm{C} / \mathrm{min}$

222 to $200^{\circ} \mathrm{C}$ and hold for 12 minutes, for a total method length including cool-down of

223 approximately 33 minutes.

Total and volatile solids were quantified in accordance with Standard Methods 2540G

225 (APHA et al., 2012). A Thermo Fisher Scientific Accumet AP85 Waterproof pH/Conductivity

226 Meter (Thermo Fisher Scientific, Waltham, MA, USA) was used to measure $\mathrm{pH}$, and was

227 calibrated on a monthly basis.

228 Samples were collected on two occasions during the analysis period and shipped to the

229 Dairy One Forage Laboratory (Ithaca, New York, USA) for quantification of acid detergent fiber

230 (ADF), neutral detergent fiber (NDF), acid detergent lignin (ADL), starch, crude fat, total

231 phosphorus (TP), and crude protein. The methods and equipment used by the Dairy One

232 laboratory are available at http://dairyone.com.

233

2.6 Comparative Analysis of Microbial Populations

Microbial population analyses were conducted applying quantitative polymerase chain reaction (qPCR) based on 16S rDNA oligonucleotide primers following an approach similar to

236 that described by Coats et al. (2012). Biomass samples were collected on four occasions from all

237 digesters (operational days 14, 23, 29, and 38). Genomic DNA was extracted from each sample 238 using the MO BIO PowerSoil ${ }^{\circledR}$ DNA Isolation Kit (MO BIO Laboratories Inc., Carlsbad, CA

239 USA). 16S rDNA-based oligonucleotide primers were used to target the three principle orders of 
240

241

242

243

244

245

246

247

248

249

250

251

252

253

254

255

256

257

258

259

260

261

262

hydrogenotrophic methanogens (Methanococcales (MCC), Methanobacteriales (MBT), and Methanomicrobiales (MMB)), the two families of acetoclastic methanogens (Methanosarcinaceae (MSC) and Methanosaetaceae (MST)), all members of the domain Archaea and Bacteria, and prokaryotes (Table 1).

qPCR was performed on a StepOne Plus ${ }^{\mathrm{TM}}$ Real-Time PCR system (Applied Biosystems, Foster City, CA, USA) using iTaq ${ }^{\mathrm{TM}}$ SYBR ${ }^{\circledR}$ Green Supermix with ROX (Bio-RAD Laboratories Inc., Hercules, CA, USA) with a total reaction volume of $25 \mu \mathrm{L}$. The qPCR process was performed under the following conditions: $3 \mathrm{~min}$ at $95^{\circ} \mathrm{C}, 45$ cycles of $30 \mathrm{~s}$ at $95^{\circ} \mathrm{C}, 45 \mathrm{~s}$ annealing (annealing temperature varied from 55 to $60^{\circ} \mathrm{C}$ depending on the primer set), and $30 \mathrm{~s}$ at $72^{\circ} \mathrm{C}$. Samples were prepared using $5 \mathrm{ng}$ of total genomic DNA, quantified using a BioTek H1 hybrid multi-mode plate reader (BioTek, Winooski, VT, USA) and targeting a $500 \mathrm{nM}$ final concentration of each primer per reaction. Annealing temperatures and primer concentrations were determined through an optimization process. All qPCR melting curves were evaluated to confirm a single melting peak, and agarose gel analysis confirmed one signal for each primer set. Amplification efficiencies were calculated for each primer set using baseline-corrected fluorescence data (StepOne software v2.0) and the LinRegPCR program (Ramakers et al., 2003). The cycle threshold was set at a constant value within the log-linear region across all samples for determination of quantification cycle $(\mathrm{Cq})$ values, i.e., the cycle number at which the fluorescence value exceeded the threshold value. Multiple qPCR 96 well plates were processed and analyzed; average amplification efficiencies, calculated for each primer set and for each AD sample (Table 1), were consistent with that observed by others (Traversi et al., 2011; Yu et al., 2006). Comparisons of target gene quantities between samples were made by calculation of a relative expression ratio (RER) following an approach similar to that described by Cikos and 
263 Koppel (2009) under the assumption that the 16S rDNA gene copy numbers for the groups being 264 compared were identical. The RER for eubacteria was calculated relative to prokaryotes. Cq 265 values for replicate samples on a given plate that differed by $> \pm 0.5$ were discarded from the 266 analyses.

\section{$267 \quad 2.7$ Statistical Methods}

Single factor or two-factor ANOVA was used to establish differences in means using

269 Microsoft Excel, with significance declared at $p<0.05$.

\section{3. Results}

271

Two integrated two-stage AD systems were deployed for this study (Figs. 1a, 1b); as

272 shown, the comparative systems ultimately included three separate ADs. The principle goal of

273 this research was to develop an enhanced understanding of the potential and viability of

274 separating fine and coarse residual solids from the fermenter for targeted, and enhanced overall,

275 methanogenesis. Results presented and discussed herein represent data collected over an 85-day

276 steady state operational period.

\section{$277 \quad 3.1$ Comparative Methane Production}

Typical methane content of AD-treated biomass ranges from 48-65\% (Ward et al., 2008).

279 Comparatively, previous investigations into this two-stage AD configuration revealed an average 280 methane content of 54\% (Coats et al., 2012). For these current investigations, methane content in 281 the biogas over the analysis period was stable for all three digesters, both individually and for the 282 combined system measurements (Table 2). The average methane content ranged from 57.1\%

283 (AD-3c; coarse solids only) to $64.4 \%$ (AD-8; fine solids) to 60.9\% (AD-6c; combined solids); of 284 note, $\mathrm{AD}$ of the fine solids generated methane content near the maximum expected for $\mathrm{AD}$ of 285 agricultural wastes (Ward et al., 2008), while even the less digestible solids stream produced 
average concentrations. After an operational period of 38 days, the biogas exhaust lines of reactors AD3-c and AD8 (System 2) were spliced together, and biogas production from both digesters was measured using a single meter; this approach allowed measurement and characterization of the combined System 2 biogas, for enhanced direct comparison with System 1. During the operational period wherein biogas was combined from the System 2 ADs, the average methane content of AD6-c (System 1) was 61.3\%, while that of System 2 was 59.9\%; the difference was statistically significant $\left(p=6.46^{*} 10^{-22}\right)$.

In addition to methane content, the methane production from both systems was quite stable over the extended analysis period, an outcome that could be considered unexpected given that raw manure (an inherently heterogeneous substance) was used as the substrate. However, such stability reinforces the value of the two-stage AD configuration, as compared to the conventional single-state approach (i.e., raw manure), and reinforces original findings (Coats et al., 2012). Over the full analysis period, average methane production from System $1(22.7 \mathrm{~L} / \mathrm{d})$ was statistically higher $\left(p=6.82 * 10^{-6}\right)$ than observed in System 2 at $20.8 \mathrm{~L} / \mathrm{d}$ (Table 2; Figure 2). Considering that methane production and yield values were actually highest for the combined solids System 1 - ultimately disproving the hypothesis driving this investigation attention turned to further data interrogation for potential explanations as to why combined solids $\mathrm{AD}$ was more productive. The remainder of this paper focuses on discussion in this regard.

\subsection{Volatile Solids Reduction and Methane Production}

Care was taken to ensure the OLRs applied (on a VS basis) to each System were similar, so that differences in VS loading did not influence the comparative operations and associated results. However, the digester OLRs were not regulated directly, and were instead controlled by the loading applied to, and the reactions occurring within, the upstream fermenters. Moreover, 
the production of fine solids by F3-c was variable, causing the loading rate of AD8 to fluctuate more than that of AD3-c and AD6-c (Fig. 3). Nevertheless, there was ultimately no statistical difference between the mass of VS applied to the two digestion systems or to their respective fermenters (Table 3).

While OLRs remained statistically the same, the observed VS destruction in System 1 was statistically higher than that of System $2(p=0.02$; Table 4$)$. Specifically examining the individual reactors, VS reduction averaged $14-17 \%$ in the fermenters (Table 4), and was subject to substantial uncertainty associated with variability in the composition of the raw manure. Note also that some of the fermenter VS reduction was due to biogas production; the methane content of biogas produced by F3-c averaged $45.8 \%+/-2.4 \%(n=10)$, while that of F6-c averaged $42.9 \%+/-1.46 \%(\mathrm{n}=5)$, with the remainder consisting primarily of carbon dioxide. Observed AD VS reduction, at 30-35\%, was slightly lower than reported values for raw dairy manure (ElMashad et al., 2008; Kaparaju \& Rintala, 2011) but comparable with previous research on this process configuration ((Coats et al., 2012); the OLR in this current study was also 24-31\% lower than the previous study). However, total VS destruction across the fermenter and AD (exceeding $45 \%$ ) was higher than typically observed for raw dairy manure, indicating the two-stage process achieves better overall capture of valuable carbon. Comparing VS destruction between digesters, AD8 (fine solids) and AD6-c (combined solids) exhibited similar reduction (approximately 34\%; Table 5), while that of AD3-c (coarse solids) was only 30.4\%. These comparative results indicate the readily biodegradable component of the coarse solids fraction was substantially smaller than that of the fine solids fraction, which could have adversely impacted methane production in the System 2 configuration. Moreover, since VS destruction in anaerobic digestion correlates directly with methane production, it would appear that separate digestion of the fine and coarse 
332 solids did not improve overall VS reduction, and instead the separation of solids streams

333 appeared to adversely impact methanogenesis (these interpretations align with the methane

334 results presented and discussed above).

335 Methane yield is a function of a range of factors, including the composition of the

336 substrate (e.g., its biodegradability), and a range of values have been reported in the literature.

337 Yields of 0.075-0.223 $\mathrm{L} \mathrm{CH}_{4} / \mathrm{g}$ VS applied were observed by Ogejo and Li (2010) digesting raw

338 dairy manure, and Hawkes et al. (1984) reported yields of 0.166-0.204 $\mathrm{L} \mathrm{CH}_{4} / \mathrm{g}$ VS applied at

339 SRTs from 5-15 days from screened dairy manure. The International Panel on Climate Change

340 (IPCC) reports an optimal value for the ultimate methane production potential of raw dairy

341 manure (i.e., optimal because that value would be generated by a biomethane potential (BMP)

342 test) of $0.240 \mathrm{~L} \mathrm{CH}_{4} / \mathrm{g} \mathrm{VS}$ applied (IPCC, 1997). Comparatively, the digestion systems examined

343 in this research processed pre-fermented organic material remaining after diverting much of the

344 soluble carbon (e.g., VFAs) to PHA production. Thus, as might be expected, the yields of

345 System 1 and System 2 normalized to the VS mass applied to the fermenters (i.e., the mass of VS

346 in the raw manure entering the system and available for combined $\mathrm{PHA}$ and $\mathrm{CH}_{4}$ production) fall

347 into the lower end of the range of yields per gram VS applied reported in the literature (Table 5);

348 gross yields were approximately $50 \%$ of the IPCC optimal yield value. However, when methane

349 production was normalized to the VS mass applied to each digester (Table 5), the values were

350 comparatively in the higher end of those typically reported, indicating very effective digester

351 performance. Moreover, methane yield on fine solids (AD8) was near the IPCC optimal, at 0.22

$352 \mathrm{~L} \mathrm{CH}_{4} / \mathrm{g}$ VS applied. Conversely, methane yield on the coarse solids fraction (which, on a mass

353 basis, was the dominant fraction), at $0.17 \mathrm{~L} \mathrm{CH}_{4} / \mathrm{g} \mathrm{VS}$ applied, significantly reduced the overall

354 average of the separate solids AD yield (compared with System 1). Combined with the VS 
355 destruction data, these results suggest that digesting coarse solids alone yields a less efficient

356 biochemical system in terms of organics degradation, which contributed to disproving the

357 research hypothesis. Note that, for this study, reported methane production volumes were

358 adjusted to reflect the presence of biogas water vapor, and also are reported in units of standard

359 temperature and pressure (STP). In contrast, most published biogas measurements in AD

360 research are frequently not reported with such corrections; biogas data reported at ambient or

361 elevated temperature/pressure would skew numbers higher, which lends additional credibility to

362 the process and results detailed herein.

$363 \quad 3.3$ VFA Analysis

364

Influent/effluent VFA concentrations are an effective and necessary process monitoring

365 parameter associated with $\mathrm{AD}$, and examination of such data can potentially explain differential

366 process performance. A healthy AD should consume nearly all available and produced VFAs,

367 with an effluent concentration less than 100-200 mg/L (Speece, 2008). Comparing Systems 1

368 and 2, average total effluent VFA concentrations were statistically similar between the two

369 fermenters $(p=0.075)$. Each digester effectively removed nearly all VFAs present in the

370 fermenter effluent (i.e., AD influent), along with any generated in the digester (Fig. 4); digester

371 effluent VFA concentrations were well below the recommended 100-200 mg/L maximum

372 (averages of $67 \mathrm{mgCOD} / \mathrm{L}(\mathrm{AD} 3-\mathrm{c}) ; 53 \mathrm{mgCOD} / \mathrm{L}$ (AD6); $6.4 \mathrm{mgCOD} / \mathrm{L}$ (AD8-c)). Of note,

373 AD8 (fine solids) exhibited the best performance of the three digesters, with effluent VFA

374 concentrations approaching non-detect. The average effluent VFA concentration of AD3-c

375 (coarse solids) was somewhat higher than that of AD6-c (combined solids), although the

376 difference was not statistically significant $(p=0.25)$. Combined, there was no statistical

377 difference in the average mass of VFAs present in the effluent of the two AD systems $(p=0.86)$. 
378 Ultimately, the low effluent VFA concentrations suggest a healthy and syntrophic microbial 379 culture in the two Systems.

What is not reflected in the influent/effluent VFA data is the relative in-process potential

381

382

383

384

385

386

387

388

389

390

391

392

393

394

395

396

397

398

399

400

to generate additional VFAs, specifically associated with the substrate; such potential could help explain the differential process performance (and associated hypothesis rejection). Indeed, characterization of the different solids fractions (Table 6) suggests that the difference in methane production between the three ADs was more likely due to the fermentative processes of hydrolysis and/or acidogenesis. Specifically, crude fat content was significantly higher in AD8 as compared with AD3-c, while influent solids to AD6-c were also relatively rich in crude fat.

Fermentation of the crude fat fraction would be an efficient metabolism for generating methane precursors (acetate and hydrogen; both for acetoclastic and hydrogenotrophic archaea).

Similarly, crude protein would generate quality methane precursors (principally acetate), and both AD8 and AD6-c exhibited protein degradation. Conversely, starch content (acetate production) would appear to have contributed more significantly to methane production in AD3-

c. Thus, it would appear that the combined solids System 1 AD received a more heterogeneous mix of methane precursor substrate to support both acetoclastic and hydrogenotrophic archaea (note that additional microbial discussion follows in the next section), which ultimately led to improved methane production (as compared with AD3-c and AD8, which received a less heterogeneous solids substrate).

\subsection{Microbial Population Comparisons}

As a final interrogation of the respective ADs, and in further search of an explanation for differential process performance, the microbial populations were examined applying qPCR.

Characterization of the microbial community within the respective systems can provide 
401 important insight into potential process functions, as demonstrated by previous studies into this

402 two-stage AD configuration (Briones et al., 2014; Coats et al., 2012). For this investigation,

403 samples for qPCR analysis of the microbial consortia were collected on days 14, 23, 29, and 38

404 from the three digesters and evaluated for archaeal species and bacteria. The relative expression

405 ratio (RER) was calculated between each $\mathrm{AD}$ configuration for each targeted gene sequence in

406 each reactor comparison combination; qPCR RER results are shown in Table 7. First considering

407 hydrogenotrophic archaea, AD8 (fine solids) was very much more enriched in the hydrogen-

408 utilizing Methanomicrobiales, and to a lesser degree Methanococcales (followed by AD6-c and,

409 to a much lower degree, AD3-c). The higher relative concentrations of these hydrogenotrophs

410 also correlated with elevated biogas methane content (Table 2); the methane content of AD8 was

411 greater than that of AD6-c, which was greater than that of AD3. The larger hydrogenotrophic

412 population would be expected to produce a biogas with a higher methane fraction, as these

413 archaea utilize carbon dioxide during methane synthesis. Greater abundance of hydrogenotrophs

414 thus appears to be correlated with the inclusion of the fine solids material in the digester feed

415 (AD8; AD6-c) and the associated production of hydrogen through $\beta$-oxidation of fats, which, as

416 noted, were present at elevated comparative levels in the fine solids (Table 6). The exception to

417 this comparative archaeal observation was order Methanobacteriales (MBT), which appeared

418 (across the four sampling periods) to generally exhibit similar concentrations in the three ADs,

419 on average. Interestingly, recent research (Danielsson et al., 2012) found the rumen of dairy

420 cows dominantly enriched with MBT; thus, it would be reasonable to expect the three ADs

421 would generally exhibit similar MBT concentrations, given the source of substrate.

422

Regarding acetoclastic methanogens (which use acetate as the methane precursor),

423 although as noted the overall VFA effluent concentrations were quite low for all ADs, effluent 
424 acetate concentrations in AD3-c were on average the highest, followed by AD6-c and AD8 (44,

42531 , and $5 \mathrm{mg} / \mathrm{L}$, respectively). The maximum specific growth rate, $\mu_{\max }$, as well as the half-

426 saturation coefficient, $\mathrm{K}_{\mathrm{s}}$, are higher in Methanosarcina than in Methanosaeta (Speece, 2008).

427 Consequently, the presence of Methanosarcina tends to correlate with higher digester effluent

428 acetate concentrations, while Methanosaeta is more likely to be found in digesters operated at

429 lower acetate concentrations (De Vrieze et al., 2012). This relationship was well reflected by the 430 qPCR data, with AD8 (lowest effluent HAc concentration) dominated by Methanosaeta, while

431 AD3-c and AD6-c were dominated by Methanosarcina; from the RER perspective, AD8-c was

432 minimally enriched for Methanosarcina. Finally, RER analysis of the archaeal population

433 suggests that all three ADs, on average across the four sampling points, were comparably

434 enriched with methanogens; these results align with the general consistency and productivity in 435 methane from all three ADs.

In addition to methanogenic archaea, comparison of relative quantities of the domain

437 Bacteria is of interest, as its members are responsible for the hydrolysis and subsequent

438 fermentation of cellulosic material (Lynd et al., 2002; Thomas et al., 2011); a digester enriched

439 with a larger bacterial population would be capable of an increased degree of cellulose

440 degradation. In this regard, qPCR results suggest that bacteria were most prevalent in AD3-c

441 (coarse solids), with AD8 and AD6-c generally exhibiting comparable concentrations. With the 442 coarse solids being more difficult to degrade (being more enriched with ADF, NDF, and starch, 443 all cellulose-based substrates; Table 6), these results suggest that the AD bacterial communities 444 developed specific to substrate and overall process needs (i.e., less digestible substrate demands 445 more bacteria); this interpretation also aligns with previous molecular interrogation of the 446 respective AD configurations (Briones et al., 2014). 


\section{Conclusions}

Research presented herein centered on the hypothesis that separately digesting fine and

449 coarse solids (vs. combined) from fermented dairy manure would improve methane production;

450 the hypothesis was disproven. While maximum biogas methane concentration was realized on

451 fine solids, combined solids AD realized enhanced VS destruction. The diverse combined-solids

452 substrate enriched for a more heterogeneous bacterial/archaeal consortium that balanced

453 fermentation and methanogenesis to yield maximum product (methane). However, results

454 suggest that targeted $\mathrm{AD}$ of the fat-rich fine solids could be a more optimal approach for

455 processing manure; alternate (non-AD) methods could then be applied to extract value from the 456 fibrous fraction.

\section{Acknowledgements}

458 The material presented and discussed herein is based upon work supported by i) the U.S.

459 Department of Agriculture under Grant Number NIFA\#2012-68002-19952, and ii) the National 460 Science Foundation under Grant Number CBET-1235885 Any opinions, findings, and

461 conclusions or recommendations expressed in this material are those of the authors and do not 462 necessarily reflect the views of the funding agencies. 


\section{References}

465

466

467

468

469

470

471

472

473

474

475

476

477

478

479

480

481

482

483

484

485

486

487

488

489

490

491

492

493

494

495

496

497

498

499

500

501

502

503

504

505

506

507

508

APHA, AWWA, WEF. 2012. Standard methods for the examination of water and wastewater. AWWA.

Betts, C.L., Ling, K.C. 2009. Cooperative Approaches for Implementation of Dairy Manure Digesters. U.S. Department of Agriculture.

Briones, A., Coats, E., Brinkman, C. 2014. Should we build "obese" or "lean" anaerobic digesters? PLoS ONE, 9(5), e97252.

Čikoš, Š., Koppel, J. 2009. Transformation of real-time PCR fluorescence data to target gene quantity. Anal. Biochem., 384, 1-10.

Coats, E.R., Ibrahim, I., Briones, A., Brinkman, C.K. 2012. Methane production on thickened, pre-fermented manure. Bioresour. Technol., 107(March), 205-212.

Coats, E.R., Loge, F.J., Wolcott, M.P., Englund, K., McDonald, A.G. 2007. Synthesis of polyhydroxyalkanoates in municipal wastewater treatment. Water Environ. Res., 79(12), 2396-2403.

Coats, E.R., Searcy, E., Feris, K., Shrestha, D., McDonald, A.G., Briones, A., Magnusson, T., Prior, M. 2013. An integrated 2-stage anaerobic digestion and biofuel production process to reduce life cycle GHG emissions from U.S. dairies. BioFPR, 7(4), 459-473.

Danielsson, R., Schnürer, A., Arthurson, V., Bertilsson, J. 2012. Methanogenic Population and CH4 Production in Swedish Dairy Cows Fed Different Levels of Forage. Appl. Environ. Microb., 78(17), 6172-6179.

De Vrieze, J., Hennebel, T., Boon, N., Verstraete, W. 2012. Methanosarcina: The rediscovered methanogen for heavy duty biomethanation. Bioresour. Technol., 112, 1-9.

El-Mashad, H.M., McGarvey, J.A., Zhang, R. 2008. Performance and microbial analysis of anaerobic digesters treating food waste and dairy manure. Biol. Eng., 1(3), 235-244.

EPA, U.S. 2003. Control of Pathogens and Vector Attraction in Sewage Sludge. EPA/625/R92/013 ed, (Ed.) U.S. EPA, U.S. EPA. Washington, D.C.

EPA, U.S. 2014. Inventory of U.S. Greenhouse Gas Emissions and Sinks: 1990-2012. U.S. Environmental Protection Agency.

EPA, U.S. 2010. U.S. Anaerobic Digester Status Report. U.S. Environmental Protection Agency.

Faulhaber, C.R., Raman, D.R., Burns, R.T. 2012. An engineering-economic model for analyzing dairy plug-flow anaerobic digesters: cost structures and policy implications. Trans. ASABE, 55(1), 201-209.

Hawkes, F.R., Rosser, B.L., Hawkes, D.L., Statham, M. 1984. Mesophilic anaerobic digestion of cattle slurry after passage through a mechanical separator - factors affecting gas yield. Agricultural Wastes, 10(4), 241-256.

Huse, S.M., Dethlefsen, L., Huber, J.A., Welch, D.M., Relman, D.A., Sogin, M.L. 2008. Exploring Microbial Diversity and Taxonomy Using SSU rRNA Hypervariable Tag Sequencing. Plos Genetics, 4(11), 10.

IPCC. 1997. Revised 1996 IPCC Guidelines for National Greenhouse Gas Inventories: Reference Manual, Vol. 3, IPCC, pp. 4.39.

Kaparaju, P., Rintala, J. 2011. Mitigation of greenhouse gas emissions by adopting anaerobic digestion technology on dairy, sow and pig farms in Finland. Renew. Energ., 36, 31-41.

Lee, C., Kim, J., Hwang, K., O'Flaherty, V., Hwang, S. 2009. Quantitative analysis of methanogenic community dynamics in three anaerobic batch digesters treating different wastewaters. Water Res., 43(1), 157-165. 
Lynd, L.R., Weimer, P.J., van Zyl, W.H., Pretorius, I.S. 2002. Microbial cellulose utilization: Fundamentals and biotechnology. Microbiol. Mol. Biol. Rev., 66(3), 506-577.

Ogejo, J.A., Li, L. 2010. Enhancing biomethane production from flush dairy manure with turkey processing wastewater. Appl. Energy, 87(10), 3171-3177.

Ramakers, C., Ruijter, J.M., Deprez, R.H.L., Moorman, A.F.M. 2003. Assumption-free analysis of quantitative real-time polymerase chain reaction (PCR) data. Neuroscience Letters, 339(1), 62-66.

Sahlstrom, L. 2003. A review of survival of pathogenic bacteria in organic waste used in biogas plants. Bioresour. Technol., 87(2), 161-166.

Sanders, D.J., Roberts, M.C., Ernst, S.C., Thraen, C.S. 2010. Digesters and demographics: Identifying support for anaerobic digesters on dairy farms. J. Dairy Sci., 93(11), 55035508.

Speece, R.E. 2008. Anaerobic biotechnology and odor/corrosion control for municipalities and industries. Fields Publishing, Inc., Nashville, Tennessee, USA.

Takai, K., Horikoshi, K. 2000. Rapid detection and quantification of members of the archaeal community by quantitative PCR using fluorogenic probes. Appl. Environ. Microbiol., 66(11), 5066-+.

Thomas, F., Hehemann, J.-H., Rebuffet, E., Czjzek, M., Michel, G. 2011. Environmental and gut Bacteroidetes: the food connection. Frontiers in Microbiology, 2.

Traversi, D., Villa, S., Acri, M., Pietrangeli, B., Degan, R., Gilli, G. 2011. The role of different methanogen groups evaluated by Real-Time qPCR as high-efficiency bioindicators of wet anaerobic co-digestion of organic waste. AMB Express, 1, 28-28.

USDA-NRCS. 2012. Agricultural Waste Management Field Handbook. U.S. Department of Agriculture, Washington, D.C.

Ward, A.J., Hobbs, P.J., Holliman, P.J., Jones, D.L. 2008. Optimisation of the anaerobic digestion of agricultural resources. Bioresource Technol., 99, 7928-7940.

Wei, L., Guho, N.M., Coats, E.R., McDonald, A.G. 2014. Characterization of poly(3hydroxybutyrate-co-3-hydroxyvalerate) biosynthesized by mixed microbial consortia fed fermented dairy manure. J. Appl. Polym. Sci., 131(11), 5516-5528.

Weiland, P. 2010. Biogas production: current state and perspectives. Appl. Microbiol. Biotechnol., 85(4), 849-860.

Yu, Y., Kim, J., Hwang, S. 2006. Use of real-time PCR for group-specific quantification of aceticlastic methanogens in anaerobic processes: Population dynamics and community structures. Biotechnol. Bioeng., 93(3), 424-433.

Yu, Y., Lee, C., Kim, J., Hwang, S. 2005. Group-specific primer and probe sets to detect methanogenic communities using quantitative real-time polymerase chain reaction. Biotechnol. Bioeng., 89(6), 670-679.

Zaks, D.P.M., Winchester, N., Kucharik, C.J., Barford, C.C., Paltsev, S., Reilly, J.M. 2011. Contribution of anaerobic digesters to emissions mitigation and electricity generation under U.S. climate policy. Environ. Sci. Technol., 45, 6735-6742. 


\section{LIST OF TABLES}

Table 1 Primers and genetic sequences used in qPCR analysis.

Table 2 Comparative mean biogas production, composition and methane yield for the ADs. Confidence intervals represent one standard deviation. Values shown for AD3-c and AD8 are based on the first 37 days of data collection.

Table 3 Average solids characteristics and $\mathrm{pH}$ in feed and effluent of each reactor. Confidence intervals represent one standard deviation.

Table 4 Average organic loading rate and VS destruction in each reactor. Confidence intervals represent one standard deviation.

Methane production normalized to grams VS applied, g VS destroyed, and liters of active digester volume. Values shown for AD3-c and AD8 are based on the first 37 days of data collection, while days 38-85 are reflected in the AD3-c+AD8 data. Confidence intervals represent one standard deviation.

Table 5 Average reactor influent/effluent composition on a percent of dry matter (percent) basis. Confidence intervals represent one standard deviation. (NDF=neutral detergent fiber; $\mathrm{ADF}=$ acid detergent fiber)

Table 6 Summary of RER comparisons between reactors. RER values for methanogens are relative to archaea; archaeal RER are relative to eubacteria; bacteria are relative to prokaryoates. Confidence intervals represent one standard deviation. Hydrogenotrophic methanogens: Methanococcales (MCC), Methanobacteriales (MBT), and Methanomicrobiales (MMB); the two families of acetoclastic methanogens (Methanosarcinaceae (MSC) and Methanosaetaceae (MST). (N.D. = no data) (qPCR replicates: day $14, \mathrm{n}=4$; day $23, \mathrm{n}=7$; day $29, \mathrm{n}=6$; day $38, \mathrm{n}=4$ ) 


\section{LIST OF FIGURES}

Figure 1a AD System 1 process flow chart (conventional two-phase AD).

Figure 1b AD System 2 process flow chart (parallel two-phase AD).

Figure 2 Daily methane production over the analysis period for System 1 (AD6-c) and System 2 (AD3-c + AD8 combined).

Figure 3 Individual digester and System 2 (AD3-c + AD8) organic loading rates.

Figure 4 Influent and effluent VFA concentrations of each reactor. 


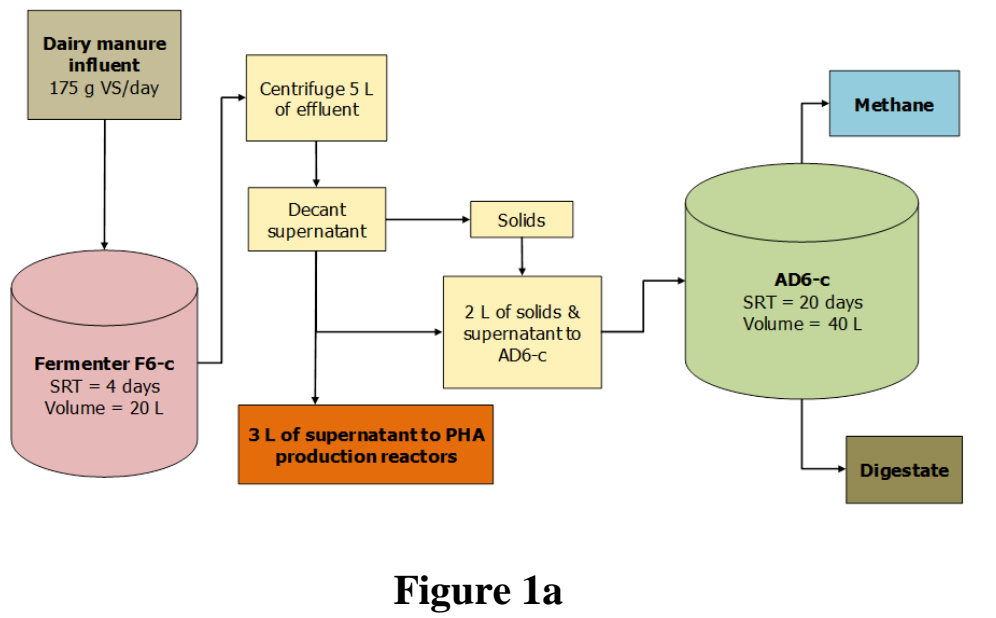

Figure 1a

$\begin{array}{ll}\text { Figure 1a } & \\ \text { Dairy manure } \\ \text { influent } \\ 175 \mathrm{~g} \text { VS/day }\end{array}$

Figure 1a

Figure 1a

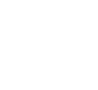

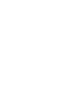
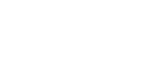

(

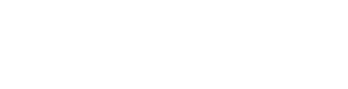


Figure 1b

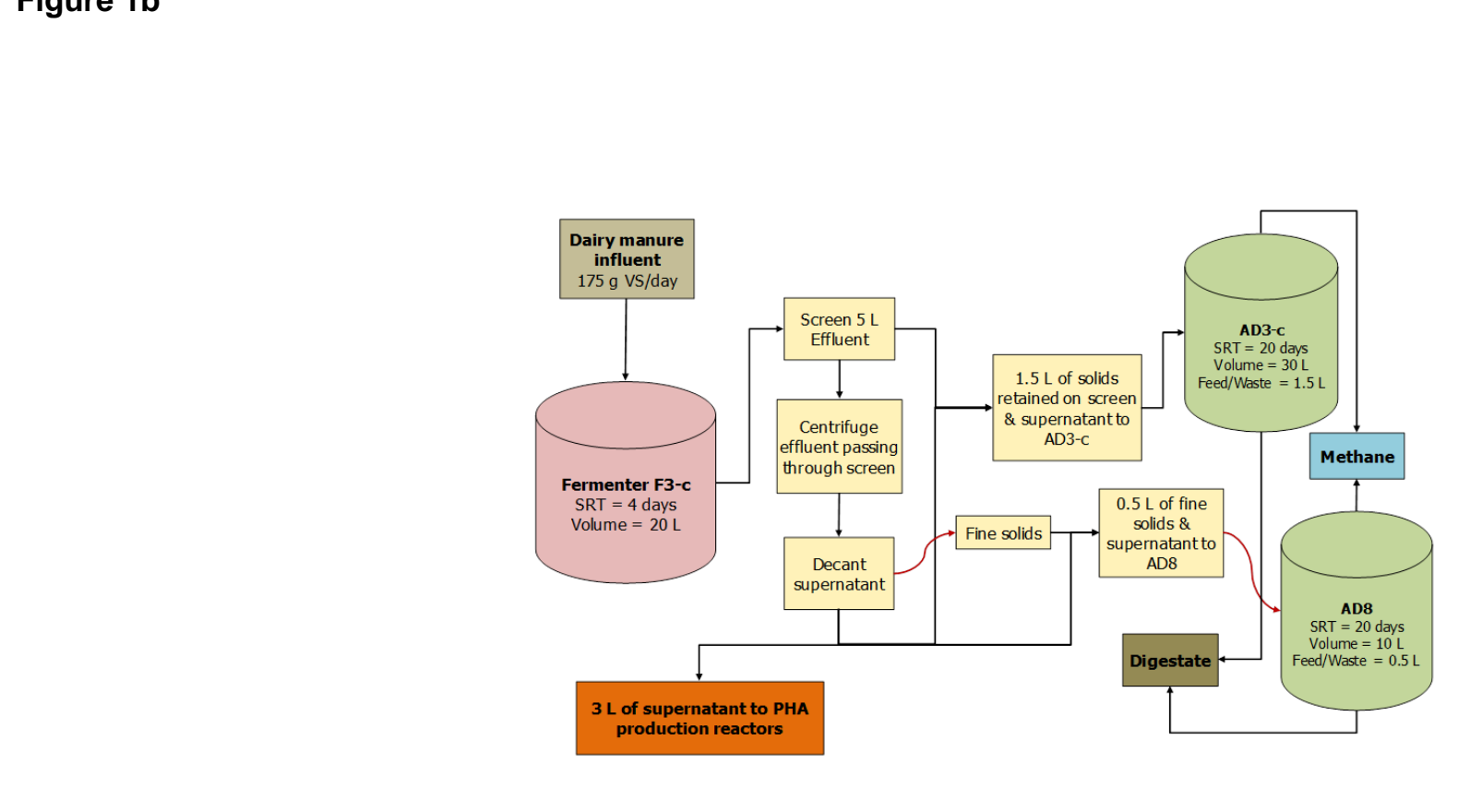

Dairy manure
influent
$175 \mathrm{~g} \mathrm{VS} / \mathrm{d}$ day

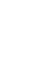

(2)

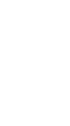
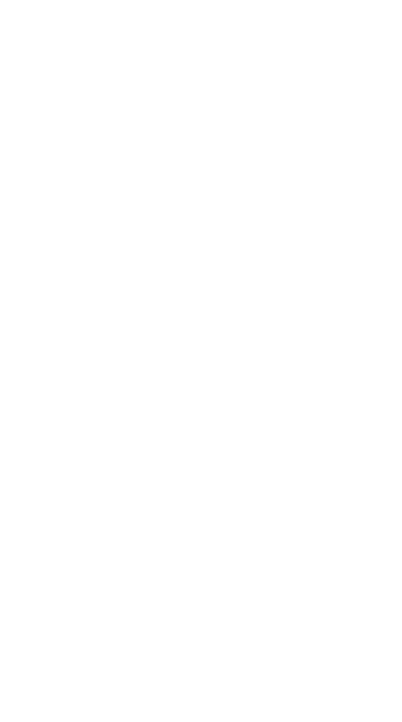

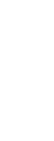

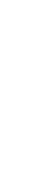

\author{
(a)
}

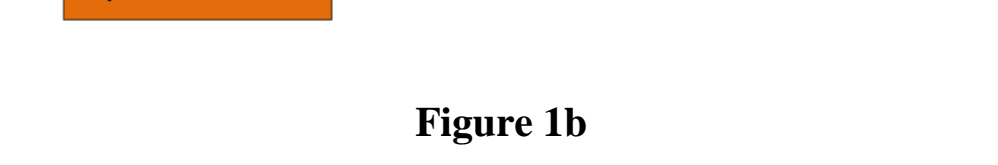

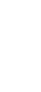
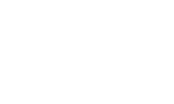
Figure 4

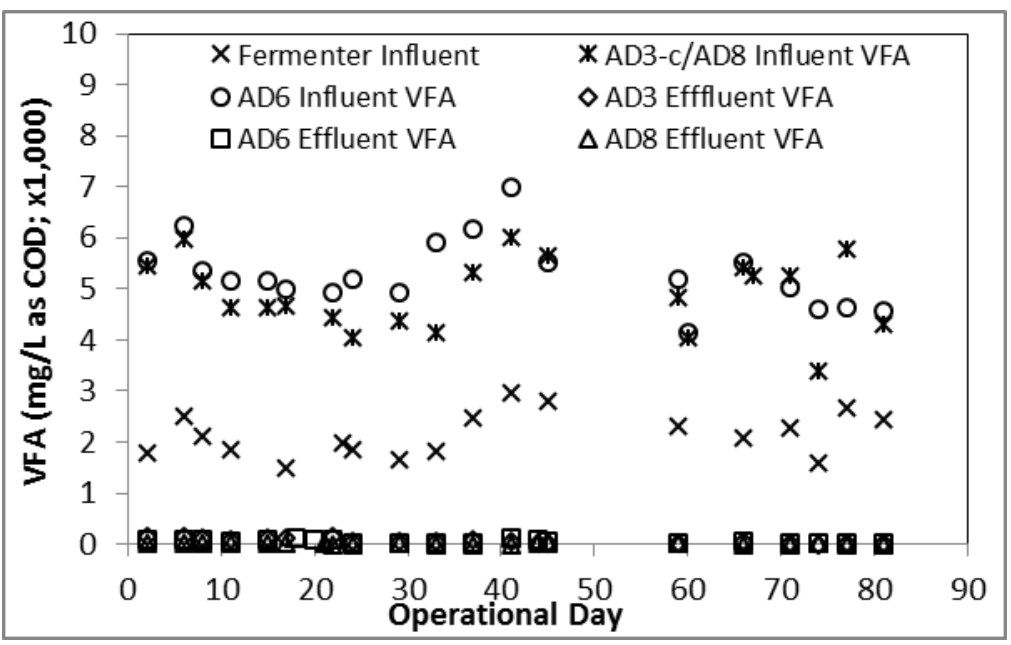

Figure 4 
Table 1

\begin{tabular}{|c|c|c|c|c|}
\hline Group & Primer & Sequence & Reference & $\begin{array}{l}\text { Amplification } \\
\text { Efficiency, \% }\end{array}$ \\
\hline \multirow{3}{*}{ Methanococcales (MCC) } & MCC 495F & TAA GGG CTG GGC AAG T & \multirow{10}{*}{$\begin{array}{l}\text { (Lee et al., 2009; Yu } \\
\quad \text { et al., 2005) }\end{array}$} & AD3-c: $68.3-83.1$ \\
\hline & MCC 832R & CAC CTA GTY CGC ARA GTT TA & & $\begin{array}{l}\text { AD6: 71.2-83.1 } \\
\text { AD8-c: } 76.0-83.1\end{array}$ \\
\hline & MBT 857F & CGW AGG GAA GCT GTT AAG T & & AD3-c: $80.1-88.4$ \\
\hline Methanobacteriales (MBT) & MBT 1196R & TAC CGT CGT CCA CTC CTT & & $\begin{array}{l}\text { AD6: 84.1-90.6 } \\
\text { AD8-c: 82.2-92.4 }\end{array}$ \\
\hline \multirow{3}{*}{ Methanomicrobiales (MMB) } & MMB 282F & ATC GRT ACG GGT TGT GGG & & AD3-c: 78.8-93.1 \\
\hline & MMB 832R & CAC CTA ACG CRC ATH GTT TAC & & $\begin{array}{l}\text { AD6: 92.7-87.9 } \\
\text { AD8-c: } 81.4-87.1\end{array}$ \\
\hline & MSC 492F & GAA ACC GYG ATA AGG GGA & & AD3-c: $81.3-92.3$ \\
\hline \multirow[t]{2}{*}{ Methanosarcinaceae (MSC) } & MSC 828R & TAG CGA RCA TCG TTT ACG & & $\begin{array}{l}\text { AD6: 82.4-91.3 } \\
\text { AD8-c: } 79.3-85.1\end{array}$ \\
\hline & MST 702F & TAA TCC TYG ARG GAC CAC CA & & AD3-c: 57.7-77.4 \\
\hline \multirow[t]{2}{*}{ Methanosaetaceae (MST) } & MST 862R & CCT ACG GCA CCR ACM AC & & $\begin{array}{l}\text { AD6: } 61.9-68.6 \\
\text { AD8-c: } 60.6-69.7\end{array}$ \\
\hline & ARC 349F & GYG CAS CAG KCG MGA AW & \multirow{2}{*}{$\begin{array}{c}\text { (Takai \& Horikoshi, } \\
\text { 2000) }\end{array}$} & AD3-c: 80.2-92.1 \\
\hline \multirow[t]{2}{*}{ All members of Archaea } & ARC 806R & GGA CTA CVS GGG TAT CTA AT & & $\begin{array}{l}\text { AD6: } 84.5-87.5 \\
\text { AD8-c: } 83.2-90.6\end{array}$ \\
\hline & BAC 338F & ACT CCT ACG GGA GGC AGC AG & \multirow[b]{2}{*}{ (Huse et al., 2008) } & AD3-c: $82.2-100.4$ \\
\hline \multirow[t]{2}{*}{ All members of Bacteria } & BAC 515R & TTA CCG CGG CTG CTG GCA C & & $\begin{array}{l}\text { AD6: 86.8-97.7 } \\
\text { AD8-c: 86.9-97.3 }\end{array}$ \\
\hline & Prok $341 \mathrm{~F}$ & CCT ACG GGR BGC ASC AG & \multirow[b]{2}{*}{ (Yu et al., 2005) } & AD3-c: $69.8-81.5$ \\
\hline Prokaryotes & Prok 806R & GGA CTA CYV GGG TAT CTA AT & & $\begin{array}{l}\text { AD6: } 65.9-82.6 \\
\text { AD8-c: } 69.7-76.5\end{array}$ \\
\hline
\end{tabular}




\section{Table 2}

\begin{tabular}{lccc} 
Reactor & Biogas $(L / d ~ @ ~ S T P)$ & Methane Content $(\%, \mathbf{v} / \mathbf{v})$ & Methane (L/d @ STP) \\
\hline AD3-c & $28.5+/-1.9(\mathrm{n}=36)$ & $57.1 \%+/-0.7 \%(\mathrm{n}=30)$ & $16.3+/-1.0(\mathrm{n}=36)$ \\
AD8 & $9.7+/-1.2(\mathrm{n}=35)$ & $64.4 \%+/-1.0 \%(\mathrm{n}=30)$ & $6.3+/-0.8(\mathrm{n}=35)$ \\
AD6-c (System 1) & $37.2+/-2.4(\mathrm{n}=76)$ & $60.9 \%+/-1.2 \%(\mathrm{n}=71)$ & $22.7+/-1.6(\mathrm{n}=76)$ \\
AD3-c + AD8 (System 2) & $35.0+/-3.2(\mathrm{n}=83)$ & $59.9 \%+/-0.6 \%(\mathrm{n}=41)$ & $20.8+/-1.8(\mathrm{n}=82)$ \\
\hline
\end{tabular}




\section{Table 3}

\begin{tabular}{|c|c|c|c|c|}
\hline Reactor & TS (\%) & VS (\% of TS) & $\begin{array}{c}\text { Total VS mass into or out } \\
\text { of reactor per day }(\mathrm{g})\end{array}$ & pH \\
\hline F3-c Influent & $\begin{array}{c}15.7 \%+/-1.5 \% \\
(\mathrm{n}=16)\end{array}$ & $\begin{array}{c}83.0 \%+/-1.4 \% \\
(\mathrm{n}=16)\end{array}$ & $\begin{array}{c}179.3+/-13.0 \\
(\mathrm{n}=16)\end{array}$ & $\begin{array}{c}7.4+/-0.6 \\
(\mathrm{n}=16)\end{array}$ \\
\hline F6-c Influent & $\begin{array}{c}15.9 \%+/-1.6 \% \\
(\mathrm{n}=16)\end{array}$ & $\begin{array}{c}83.1 \%+/-1.4 \% \\
(\mathrm{n}=16)\end{array}$ & $\begin{array}{c}182.1+/-13.1 \\
(\mathrm{n}=16)\end{array}$ & $\begin{array}{c}7.4+/-0.4 \\
(\mathrm{n}=16)\end{array}$ \\
\hline F3-c Effluent & $\begin{array}{c}3.7 \%+/-0.3 \% \\
\quad(\mathrm{n}=16)\end{array}$ & $\begin{array}{c}81.4 \%+/-1.3 \% \\
(\mathrm{n}=16)\end{array}$ & $\begin{array}{c}153.5+/-8.8 \\
(\mathrm{n}=16)\end{array}$ & $\begin{array}{c}6.7+/-0.1 \\
(\mathrm{n}=16)\end{array}$ \\
\hline F6-c Effluent & $\begin{array}{c}3.6 \%+/-0.2 \% \\
\quad(n=16)\end{array}$ & $\begin{array}{c}81.2 \%+/-1.1 \% \\
(\mathrm{n}=16)\end{array}$ & $\begin{array}{l}151.1+/-6.8 \\
(\mathrm{n}=16)\end{array}$ & $\begin{array}{c}6.6+/-0.1 \\
(\mathrm{n}=16)\end{array}$ \\
\hline AD3-c Influent & $\begin{array}{c}6.6 \%+/-0.3 \% \\
(\mathrm{n}=16)\end{array}$ & $\begin{array}{c}88.6 \%+/-1.3 \% \\
(\mathrm{n}=16)\end{array}$ & $\begin{array}{l}94.3+/-4.8 \\
\quad(\mathrm{n}=16)\end{array}$ & $\begin{array}{c}6.8+/-0.2 \\
(\mathrm{n}=16)\end{array}$ \\
\hline AD6-c Influent & $\begin{array}{c}6.8 \%+/-0.4 \% \\
(\mathrm{n}=16)\end{array}$ & $\begin{array}{c}85.7+/-1.3 \% \\
(\mathrm{n}=16)\end{array}$ & $\begin{array}{c}123.2+/-6.4 \\
(\mathrm{n}=16)\end{array}$ & $\begin{array}{c}6.8+/-0.1 \\
(\mathrm{n}=16)\end{array}$ \\
\hline AD8 Influent & $\begin{array}{c}7.2 \%+/-1.1 \% \\
\quad(\mathrm{n}=16)\end{array}$ & $\begin{array}{c}77.3 \%+/-1.6 \% \\
(\mathrm{n}=16)\end{array}$ & $\begin{array}{l}28.1+/-4.0 \\
(\mathrm{n}=16)\end{array}$ & $\begin{array}{c}6.9+/-0.1 \\
(\mathrm{n}=15)\end{array}$ \\
\hline AD3-c Effluent & $\begin{array}{c}5.0 \%+/-0.2 \% \\
(\mathrm{n}=16)\end{array}$ & $\begin{array}{c}85.5 \%+/-1.0 \% \\
(\mathrm{n}=16)\end{array}$ & $\begin{array}{l}65.5+/-2.1 \\
(\mathrm{n}=15)\end{array}$ & $\begin{array}{c}7.3+/-0.1 \\
(\mathrm{n}=16)\end{array}$ \\
\hline AD6-c Effluent & $\begin{array}{c}4.9 \%+/-0.2 \% \\
(\mathrm{n}=17)\end{array}$ & $\begin{array}{c}81.2 \%+/-1.6 \% \\
(\mathrm{n}=17)\end{array}$ & $\begin{array}{c}80.0+/-2.3 \\
(\mathrm{n}=14)\end{array}$ & $\begin{array}{c}7.4+/-0.1 \\
(\mathrm{n}=17)\end{array}$ \\
\hline AD8 Effluent & $\begin{array}{l}5.2 \%+/-0.4 \% \\
\quad(\mathrm{n}=16)\end{array}$ & $\begin{array}{c}70.5 \%+/-1.4 \% \\
(\mathrm{n}=16)\end{array}$ & $\begin{array}{l}18.2+/-1.1 \\
(\mathrm{n}=16)\end{array}$ & $\begin{array}{c}7.6+/-0.1 \\
(\mathrm{n}=16)\end{array}$ \\
\hline
\end{tabular}




\section{Table 4}

\begin{tabular}{|c|c|c|c|c|c|}
\hline Reactor & $\overline{O L R}(\mathrm{~g} \mathrm{VS} / \mathrm{L} * d)$ & VS Destruction (\%) & $\begin{array}{c}\mathrm{L} \mathrm{CH}_{4} / \mathrm{g} \text { VS applied to } \\
\text { digester }\end{array}$ & $\begin{array}{c}\mathrm{L} \mathrm{CH}_{4} / \mathrm{g} \mathrm{VS} \text { applied to } \\
\text { fermenter }\end{array}$ & $\mathrm{L} \mathrm{CH}_{4} / \mathrm{g}$ VS destroyed \\
\hline$\overline{\text { F3-c }}$ & $9.0+/-0.7(\mathrm{n}=16)$ & $14.0 \%+/-7.1 \%(\mathrm{n}=16)$ & -- & -- & $\overline{--}$ \\
\hline F6-c & $9.1+/-0.7(\mathrm{n}=16)$ & $16.8 \%+/-5.6 \%(\mathrm{n}=16)$ & -- & -- & -- \\
\hline AD3-c (coarse solids) & $3.1+/-0.2(\mathrm{n}=16)$ & $30.4 \%+/-4.2 \%(\mathrm{n}=15)$ & $0.17+/-0.01$ & N/A & $0.55+/-0.08$ \\
\hline AD8 (fine solids) & $2.8+/-0.4(\mathrm{n}=16)$ & $34.2 \%+/-9.0 \%(\mathrm{n}=16)$ & $0.22+/-0.05$ & N/A & $0.55+/-0.24$ \\
\hline $\begin{array}{l}\text { AD6-c (System 1; } \\
\text { combined solids) }\end{array}$ & $3.1+/-0.2(n=16)$ & $34.9 \%+/-3.4 \%(\mathrm{n}=14)$ & $0.18+/-0.02$ & $0.12+/-0.01$ & $0.52+/-0.08$ \\
\hline AD3-c + AD8 (System 2) & $3.1+/-0.2(\mathrm{n}=16)$ & $31.6 \%+/-4.2 \%(n=15)$ & $0.17+/-0.02$ & $0.12+/-0.01$ & $0.54+/-0.11$ \\
\hline
\end{tabular}


Table 5

\begin{tabular}{|c|c|c|c|c|c|c|}
\hline $\begin{array}{l}\text { Sample Location } \\
(\mathrm{n}=2)\end{array}$ & Crude Protein & ADF & NDF & Crude Fat & Lignin & Starch \\
\hline $\begin{array}{l}\text { Fermenter } \\
\text { Influent }\end{array}$ & $17.7 \%+/-1.5 \%$ & $31.1 \%+/-4.3 \%$ & $42.0 \%+/-0.4 \%$ & $2.1 \%+/-0.1 \%$ & $10.9 \%+/-2.7 \%$ & $4.9 \%+/-2.1 \%$ \\
\hline F3-c Effluent & $18.7 \%+/-3.8 \%$ & $33.1 \%+/-1.9 \%$ & $47.4 \%+/-3.5 \%$ & $3.6 \%+/-1.0 \%$ & $12.5 \%+/-2.4 \%$ & $0.6 \%+/-0.4 \%$ \\
\hline F6-c Effluent & $19.4 \%+/-2.3 \%$ & $32.5 \%+/-1.0 \%$ & $44.1 \%+/-2.0 \%$ & $4.1 \%+/-0.2 \%$ & $12.2 \%+/-0.4 \%$ & $0.6+/-0.4 \%$ \\
\hline AD3-c Influent & $10.7 \%+/-0.4 \%$ & $46.0 \%+/-0.5 \%$ & $64.1 \%+/-4.2 \%$ & $1.8 \%+/-0.1 \%$ & $16.0 \%+/-0.9 \%$ & $2.4 \%+/-0.1 \%$ \\
\hline AD3-c Effluent & $12.5 \%+/-0.9 \%$ & $54.1 \%+/-2.1 \%$ & $64.1 \%+/-2.8 \%$ & $1.2 \%+/-0.1 \%$ & $23.2 \%+/-2.1 \%$ & $0.5 \%+/-0.1 \%$ \\
\hline AD8 Influent & $30.4 \%+/-0.1 \%$ & $20.9 \%+/-0.1 \%$ & $37.9 \%+/-1.2 \%$ & $5.3 \%+/-1.1 \%$ & $9.2 \%+/-0.4 \%$ & $0.3 \%+/-0.3 \%$ \\
\hline AD8 Effluent & $26.6 \%+/-1.3 \%$ & $29.4 \%+/-2.0 \%$ & $37.3 \%+/-1.4 \%$ & $1.5 \%+/-1.6 \%$ & $15.3 \%+/-1.5 \%$ & $0.6 \%+/-0.1 \%$ \\
\hline AD6-c Influent & $17.1 \%+/-1.8 \%$ & $42.1 \%+/-4.1 \%$ & $56.6 \%+/-4.8 \%$ & $2.8 \%+/-0.8 \%$ & $16.7 \%+/-3.2 \%$ & $1.4 \%+/-1.1 \%$ \\
\hline AD6-c Effluent & $15.8 \%+/-0.8 \%$ & $46.1 \%+/-0.3 \%$ & $57.9 \%+/-5.4 \%$ & $1.3 \%+/-0.2 \%$ & $21.7 \%+/-1.1 \%$ & $0.4 \%+/-0.1 \%$ \\
\hline
\end{tabular}


Table 6

\begin{tabular}{|c|c|c|c|c|c|c|c|c|}
\hline Contrast & $\begin{array}{c}\text { Operational } \\
\text { Day }\end{array}$ & MCC & MBT & MMB & MSC & MST & ARC & BAC \\
\hline \multirow{4}{*}{$\begin{array}{l}\text { AD3-c vs. } \\
\text { AD6-c }\end{array}$} & 14 & N.D. & $0.67(0.33)$ & $0.26(0.08)$ & $0.65(0.17)$ & $0.63(0.34)$ & $1.66(1.38)$ & $5.42(4.40)$ \\
\hline & 23 & $0.22(0.06)$ & $0.81(0.24)$ & $0.30(0.18)$ & $0.49(0.15)$ & $0.16(0.16)$ & $1.18(0.29)$ & $2.02(0.28)$ \\
\hline & 29 & N.D. & $2.05(0.19)$ & $0.37(0.05)$ & $0.75(0.06)$ & $0.24(0.03)$ & $0.54(0.07)$ & $2.10(0.56)$ \\
\hline & 38 & $0.24(0.01)$ & $0.91(0.19)$ & $0.92(0.16)$ & $5.97(2.23)$ & $1.72(1.82)$ & $0.55(0.12)$ & $3.08(0.87)$ \\
\hline \multirow{4}{*}{$\begin{array}{l}\text { AD8 vs. } \\
\text { AD6-c }\end{array}$} & 14 & $0.63(0.01)$ & $0.87(0.22)$ & $1.64(0.27)$ & $0.16(0.14)$ & $3.20(1.67)$ & $0.84(0.31)$ & $1.81(0.20)$ \\
\hline & 23 & $1.43(0.25)$ & $2.14(1.20)$ & $8.40(5.84)$ & $0.48(0.10)$ & N.D. & $0.28(0.24)$ & $0.22(0.05)$ \\
\hline & 29 & N.D. & $1.36(0.19)$ & $2.50(0.10)$ & $0.08(0.02)$ & $1.31(0.78)$ & $0.88(0.10)$ & $0.91(0.09)$ \\
\hline & 38 & $0.39(0.00)$ & $0.73(0.05)$ & $2.12(0.23)$ & $0.08(0.04)$ & $2.95(2.59)$ & $1.91(0.16)$ & $2.34(0.55)$ \\
\hline \multirow{4}{*}{$\begin{array}{l}\text { AD8 } \\
\text { vs.AD3-c }\end{array}$} & 14 & $2.71(1.19)$ & $1.44(0.40)$ & $6.05(0.22)$ & $0.25(0.05)$ & $7.25(5.78)$ & $0.73(0.43)$ & $0.53(0.36)$ \\
\hline & 23 & $6.75(0.68)$ & $3.41(1.93)$ & $41.2(29.5)$ & $1.33(0.36)$ & N.D. & $0.22(0.19)$ & $0.10(0.02)$ \\
\hline & 29 & $13.38(4.49)$ & $0.67(0.14)$ & $6.99(1.24)$ & $0.13(0.04)$ & $6.47(3.29)$ & $1.65(0.31)$ & $0.45(0.10)$ \\
\hline & 38 & $1.60(0.05)$ & $0.83(0.14)$ & $2.36(0.38)$ & $0.01(0.00)$ & $3.03(1.75)$ & $3.53(0.65)$ & $0.81(0.30)$ \\
\hline $\begin{array}{l}\text { Summary } \\
\text { (Digesters) }\end{array}$ & & $8>6>3$ & $6 \sim 8 \sim 3$ & $8>6>3$ & $6>3>8$ & $8>6>3$ & $6 \sim 8 \sim 6$ & $3>8 \sim 6$ \\
\hline
\end{tabular}

